\title{
Identification of the Oxidative Products and Ozonolysis Pathways of Polyphenols in Peanut Skins
}

\author{
Enjie Diao, Xiangzhen Shen, Zheng Zhang, Ning Ji, Wenwen Ma, Haizhou Dong* \\ College of Food Science and Engineering, Shandong Agricultural university, Taian, People’ Republic of China \\ *Corresponding author: haizhoudong@126.com
}

Received March 11, 2014; revised March 20, 2014; accepted March 23, 2014

\begin{abstract}
Many studies have proved that ozone can decompose aflatoxins in peanuts, while polyphenols in peanut skins can also be destroyed due to its strong oxidative capacity. The polyphenols and their oxidative products in the peanut skin extracts at different ozonated times were separated and identified by HPLC-Q-TOF/MS. Based on the accurate molecular weight from mass spectrogram, and consulted the reported literatures, nine polyphenols and nine main oxidative products were identified in the peanut skins. According to the oxidative mechanism of phenols and the Criegee mechanism of ozonolysis, the ozonolysis pathways of nine polyphenols were proposed. The structures of oxidative products showed that ozone can destroy the polyphenols, so the effects of ozone treatment on the peanut skins should be considered by processors in the detoxification of aflatoxin-contaminated peanuts.
\end{abstract}

Keywords: polyphenols, ozone, oxidative product, criegee mechanism, peanut skin

Cite This Article: Enjie Diao, Xiangzhen Shen, Zheng Zhang, Ning Ji, Wenwen Ma, and Haizhou Dong, "Identification of the Oxidative Products and Ozonolysis Pathways of Polyphenols in Peanut Skins." Journal of Food and Nutrition Research, vol. 2, no. 3 (2014): 101-108. doi: 10.12691/jfnr-2-3-2.

\section{Introduction}

Polyphenols are natural components in peanut skins that possess beneficial properties acting as natural antioxidants, colorants, antimicrobials and vasodilators $[1,2,3]$. In the storage of peanuts, the polyphenol contents in peanut skins are influenced by temperature, oxygen, light, enzyme, metallic ions $[4,5]$.

Peanuts are widely consumed in China owning to their high nutritional values and good taste. However, they are often contaminated by aflatoxins before or after harvest when being exposed to a high humidity and temperature environment. Aflatoxins are associated with various diseases, such as aflatoxicosis and cancer in domestic animals and humans throughout the world [6]. It is not always possible to prevent peanuts from being contaminated by toxigenic fungi, so physical, chemical and biological methods have been developed to remove or degrade aflatoxins in contaminated products $[7,8,9]$.

Ozone as a detoxification agent has been widely used to decompose aflatoxins in foods due to its many advantages, such as high detoxification efficiency, reactivity, penetrability, and spontaneous decomposition into a non-toxic product (oxygen) without forming any hazardous residues on the treated products $[10,11,12]$.

However, ozone is a strong oxidant $(2.07 \mathrm{mV})$ after fluorine [13], which can also destroy polyphenols in foods $[2,14]$. At present, the oxidative products and ozonolysis pathways of polyphenols in peanut skins have not been studied and reported. So, the objectives of this study were to identify the polyphenols and their oxidative products in peanut skins by HPLC-Q-TOF/MS, and then deduced the ozonolysis pathways of polyphenols based on their oxidative products.

\section{Materials and Methods}

\subsection{Materials}

Unpeeled peanuts (Arachis hypogaea, Baisha variety) were purchased from local market. Peanut skins were obtained by artificial peeling and freeze-dried $(<1 \%$ of moisture content), and then stored in a dark at $4^{\circ} \mathrm{C}$ until analysis.

Methanol (HPLC-grade), was purchased from Shandong Yuwang company, China. Chloroform, ethanol, ethyl acetate, glacial acetic acid were all analytical-grade, and obtained from Tianjin Sitong company. Water was purified using a Aike Lab pure water system (Taiwan, China).

\subsection{Methods}

\subsubsection{Ozone Treatment of Peanut skins}

Peanut skins were ozonated according to the procedure provided by Diao et al. [15] using a self-made ozone treatment system (Figure 1). Briefly, $300 \mathrm{~g}$ of peanut skins were put into the ozonation column and treated by ozone ( $50 \mathrm{mg} / \mathrm{L}$ of ozone at a flow rate of $5 \mathrm{~L} / \mathrm{min}$ ) for 60 h. $60 \mathrm{~g}$ samples were taken from the ozonation column at $12 \mathrm{~h}$ intervals, and another $60 \mathrm{~g}$ sample without being treated by ozone was taken as the control. The control and 
treated samples were packed in black polyethylene bags and stored in the dark at $4^{\circ} \mathrm{C}$.

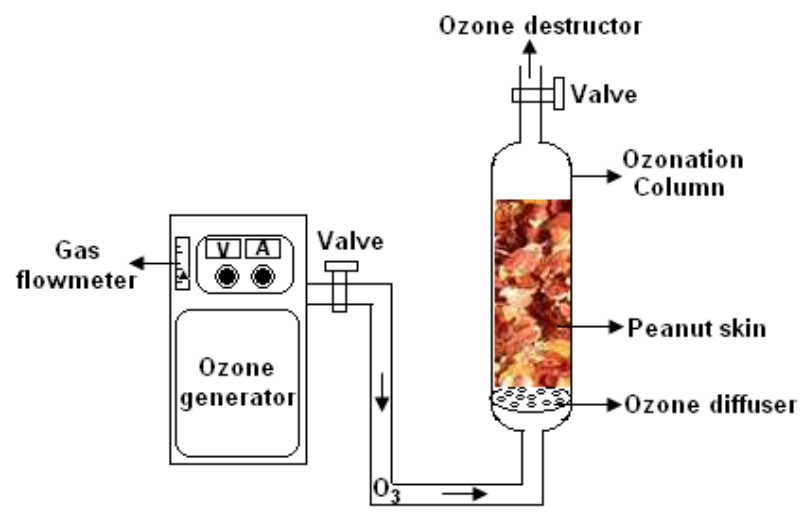

Figure 1. Schematic of ozone treatment system

\subsubsection{Separation and Purification of Polyphenols in Peanut skins}

The polyphenols were extracted by the method of Yu et al. with minor modification [1]. Briefly, the ozonated peanut skins at different exposure times were milled into fine powder (pass 60 meshes) with a grinder (XW-25, Jiuyang, Shanghai). The milled skins (10.0 g) were extracted with $200 \mathrm{~mL} \mathrm{80 \%} \mathrm{(v/v)} \mathrm{methanol} \mathrm{in} \mathrm{water} \mathrm{with}$ the help of ultrasound at $25 \mathrm{kHz}$ for $30 \mathrm{~min}$ at ambient temperature. The slurry was vacuum-filtered using 0.22 $\mu \mathrm{m}$ filter membrane, and then methanol was evaporated from the filtrate under reduced pressure using a rotary evaporator (R-1001, Greatwall, Zhengzhou) at $35^{\circ} \mathrm{C}$. After removing of the methanol, the crude extract was redissolved in $50.0 \mathrm{~mL}$ deionized water. $50.0 \mathrm{~mL}$ chloroform were added in the crude extract solution to remove lipids using a separatory funnel, and then $50.0 \mathrm{~mL}$ ethyl acetate were added in the water phase to separate the phenols from water. The water phase was removed, and the ethyl acetate was evaporated under reduced pressure using the rotary evaporator at $35^{\circ} \mathrm{C}$. The extract was redissolved in $50.0 \mathrm{~mL}$ methanol and then was vacuumfiltered using $0.22 \mu \mathrm{m}$ filter membrane. The all resulting extracts were stored in glass containers wrapped in foil at $4^{\circ} \mathrm{C}$ until used, respectively. The whole processes were completed under dim light to minimize light induced degradation of polyphenols.

\subsubsection{Identification of Polyphenols and Oxidative Products by HPLC-Q-TOF/MS}

The extracts of peanut skins were analyzed using a LC 1200 high performance liquid chromatography (Agilent, Palo Alto, CA) equipped with an autoinjector and a quaternary HPLC pump. Chromatography was performed on a $4.6 \times 250 \mathrm{~mm}$ inner diameter, $5 \mu \mathrm{m}$, VP-ODS C18 column. The injection volume was $10.0 \mu \mathrm{L}$. The mobile phase was $0.5 \%$ glacial acetic acid in water (A) and $0.5 \%$ glacial acetic acid in methanol (B). The gradient parameters used were as follows: elution rate of 1.0 $\mathrm{mL} / \mathrm{min}$, with \%(B)=10-20\% (0-5 min), 20-50\% (6-20 min), $50-80 \%$ (21-30 min), 80\% (31-35 min), 80-10\% (36-40 min), and 10\% (41-45 min).

In order to identify the polyphenols and their oxidative products in peanut skins, Q-TOF/MS was used to determine their molecular weights. It was performed on a
Q-TOF/MS equipped with a dual electrospray interface (Agilent 6520). TOF/MS analysis was performed in a negative-ion mode using full scan mode and the mass range of $\mathrm{m} / \mathrm{z}$ 100-2000. The optimized conditions were as follows: capillary and fragmentor voltages were $3500 \mathrm{~V}$ and $175 \mathrm{~V}$, respectively; the skimmer voltage was $65.0 \mathrm{~V}$; the flow rate of drying gas $\left(\mathrm{N}_{2}\right)$ was $12.0 \mathrm{~L} / \mathrm{min}$; drying gas temperature was $350^{\circ} \mathrm{C}$; nebulizer was 35 psi, and octopole radio frequency was $750 \mathrm{~V}$. The data station operating software used was the Mass Hunter Workstation software (version B.04.00). A reference mass solution containing reference ions 112.9856 and 1033.9881 was used to maintain mass accuracy during the run time.

\section{Results and Discussion}

\subsection{Identification of Polyphenols and Oxidative Products by LC-Q-TOF/MS}

LC-Q-TOF-MS has been widely used to analyze and identify organic compounds and their degradation products of food contaminants in many literatures [15,16,17,18]. Qiu et al. [19] and Appeldoorn et al. [20] have identified the polyphenols in peanut skins/shell by LC-ESI/MS, Maldi-TOF/MS, and DPPH-HPLC-DADTOF/MS, respectively. In addition, Palafox-Carlos et al. [21], Sarnoski et al. [22], Reed, [23] and Lazarus et al. [24] had used LC-MS to separate, identify and quantify the major phenolic compounds in mango fruit and peanut skins. Lou et al. [25,26] had also identified the A-type and B-type polyphenols from peanut skins using the NMR spectra.

For this experiment, HPLC-Q-TOF/MS was used to identify the polyphenols in the peanut skins. Firstly, LC was used to separate the polyphenols and their oxidative products (OPs) in peanut skin extracts, and the base peak chromatogram of separated polyphenols is presented in Figure 2.

Seen from Figure 2 A, nine polyphenols were separated from the control peanut skin extract. At $12 \mathrm{~h}$ of ozonation time, the peak areas of most polyphenols separated were decreased due to the oxidative role of ozone excepted for polyphenols 5, 7, and 8 (Figure $3 \mathrm{~A}$ ), which were increased probably due to the release of phenolic compounds ozone-induced previously bound within the various cellular components of peanut skins, or the degradation of larger phenolic compounds into smaller ones $[1,27,28,29,30]$. During the whole ozonation process, nine OPs were separated from ozonated peanut skin extracts, and their peak areas were increased generally, especially the OP7, which increased greater than those of other OPs (Figure $3 \mathrm{~B}$ ). Seen from Figure 3, the peak areas of polyphenols were decreased with the increase of ozonation time, while those of OPs were increased firstly and then decreased due to the further ozonolysis of OPs. The polyphenols 2 and 6 were completely decomposed at $36 \mathrm{~h}$ and $48 \mathrm{~h}$ of ozonation times, respectively, and the OP3, OP8, and OP9 were completely degraded at $60 \mathrm{~h}$ and $48 \mathrm{~h}$ of ozonated times, respectively. Therefore, ozone treatment can severely destroy the polyphenols in peanut skins, and their OPs can be further decomposed completely by ozone within enough time. 

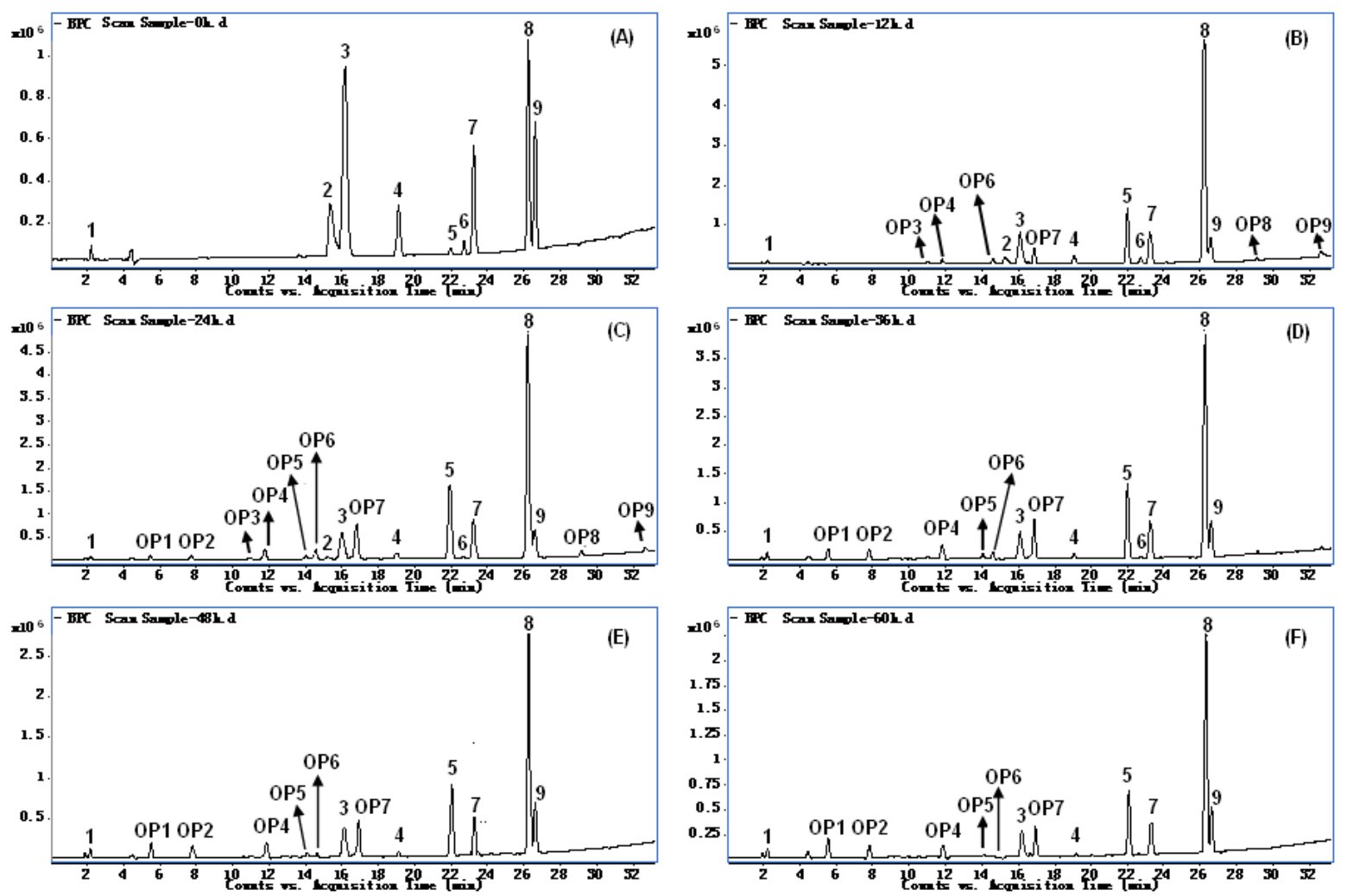

Figure 2. Base peak chromatogram of polyphenols and their oxidative products in the peanut skins at $0 \mathrm{~h} \mathrm{(A),} 12 \mathrm{~h} \mathrm{(B),} 24 \mathrm{~h}$ (C), $36 \mathrm{~h}$ (D), $48 \mathrm{~h}$ (E), and $60 \mathrm{~h}(\mathrm{~F})$ of ozonation times
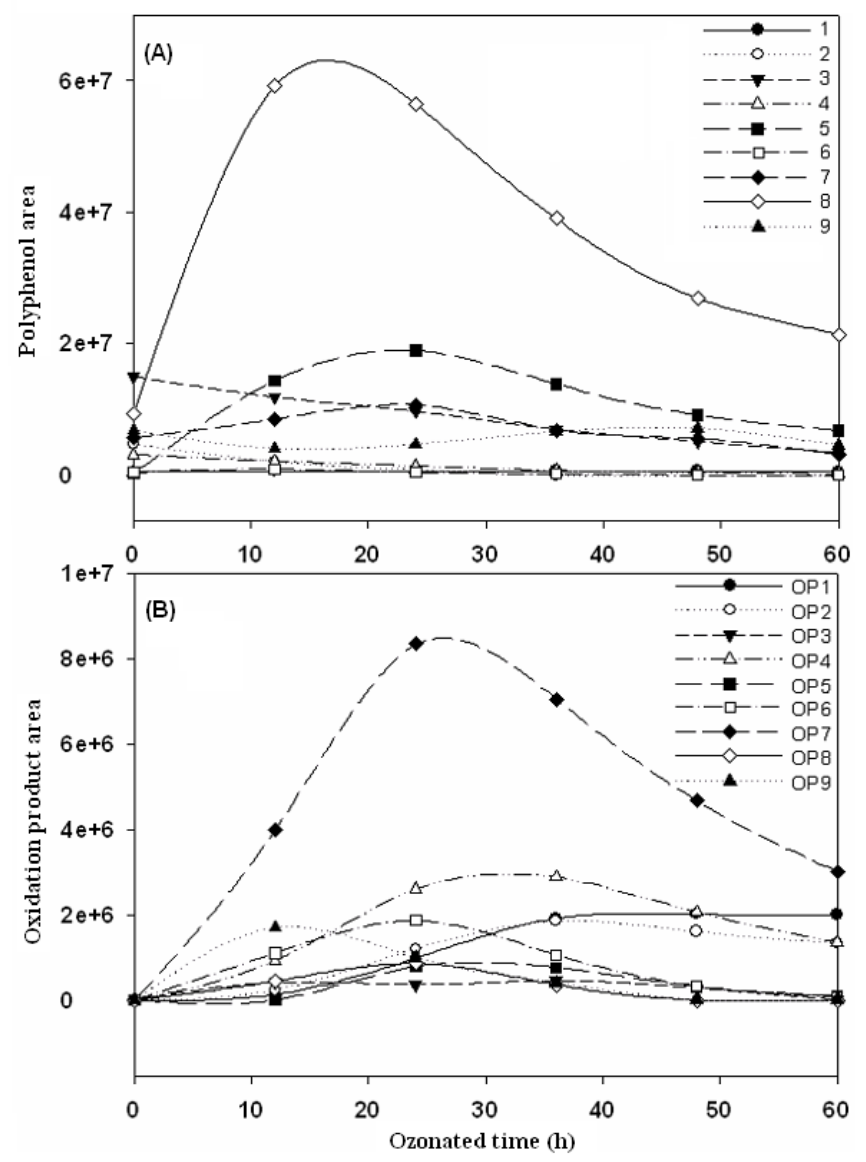

Figure 3. Peak areas of polyphenols (A) and their oxidative products (B) in the peanut skins at different ozonation times 


\subsection{Structural Identification of Polyphenols and Oxidative Products}

To confirm the structures of polyphenols and their OPs, it is important to further analyze their accurate masses. QTOF/MS of the polyphenols and their OPs were performed to pass to the collision cell using the ionfiltering function of Q-TOF. The accurate masses and molecular formulas of these compound ions (Table 1) were obtained by using the mass calculator and formula calculator, two functions of Agilent Mass Hunter qualitative analysis software. Based on the accurate masses of the compound ions and referred to the reported literatures, the structures of polyphenols and their OPs were deduced preliminary and presented in Figure 4.

Seen from the Figure 4, the peanut skin extracts contain some smaller polyphenols, such as 1,2,3,5tetrahydroxybenzene (No. 1), shikimic acid (No. 5), 1,4dihydroxynaphthalene (No. 6), and 5-hydroxy-2-methyl1,4-naphtoquinone (No. 8), and some larger ones, such as dimer (No. 3 and No. 4) or trimer (No. 2) of flavan-3-ols and flavanone trimer (No. 9). No. 7 is a conjugate of epigallocatechin gallate and gallic acid [31]. Most OPs of polyphenols are ketonic acids (OP1, OP2, OP4, and OP7), phenolic acids (OP3), quinones (OP5 and OP6), and mixed acids (OP8 and OP9). They could be further oxidized to the final products $\mathrm{CO}_{2}$ and $\mathrm{H}_{2} \mathrm{O}$ within an enough ozonation time [32,33]. In addition, some intermediate products were produced in the ozonation process, which could not be detected due to their lower contents or were rapidly oxidized to other products by ozone.

\subsection{Ozonolysis Pathways of Polyphenols in Peanut Skins}

According to the structural identification of polyphenols and their OPs in the peanut skin extracts, the ozonolysis pathways of polyphenols present in peanut skins are proposed. The ozonolysis pathways of 1,2,3,5tetrahydroxybenzene (No. 1), procyanidin trimer (No. 2) and procyanidin dimer (No. 3 and No. 4) were presented in Figure 5. The 1,2,3,5-tetrahydroxybenzene was firstly oxidized to cyclohexanehexaone by ozone based on the oxidative mechanism of phenols, and then it was decomposed to 2,3-diketo-succinic acid (OP4) and mesoxalic acid (OP1).

Table 1. Identification of the polyphenols and their oxidative products in the peanut skins during ozone treatment ${ }^{a}$

\begin{tabular}{|c|c|c|c|c|c|c|c|}
\hline $\begin{array}{l}\text { Peak } \\
\text { No. }\end{array}$ & $\begin{array}{l}\text { Retention } \\
\text { time (min) }\end{array}$ & $\begin{array}{l}\text { Molecular } \\
\text { formula }\end{array}$ & $\begin{array}{l}\text { Observed } \\
\operatorname{mass}^{b}(m / z)\end{array}$ & $\begin{array}{l}\text { Calculated } \\
\operatorname{mass}^{b}(m / z)\end{array}$ & $\begin{array}{c}\text { Mass } \\
\text { difference } \\
\text { (ppm) }\end{array}$ & $\begin{array}{l}\text { Score }^{c} \\
(\%)\end{array}$ & Proposed Products [2,19-26,31] \\
\hline 1 & 2.23 & $\mathrm{C}_{6} \mathrm{H}_{6} \mathrm{O}_{4}$ & 141.0165 & 141.0163 & -1.42 & 100 & 1,2,3,5-Tetrahydroxybenzene \\
\hline OP1 & 5.51 & $\mathrm{C}_{3} \mathrm{H}_{2} \mathrm{O}_{5}$ & 117.0194 & 117.0190 & -3.42 & 100 & Mesoxalic acid \\
\hline OP2 & 7.76 & $\mathrm{C}_{4} \mathrm{H}_{4} \mathrm{O}_{5}$ & 131.0352 & 131.0346 & -4.58 & 100 & Ketosuccinic acid \\
\hline OP3 & 10.94 & $\mathrm{C}_{7} \mathrm{H}_{6} \mathrm{O}_{4}$ & 153.0192 & 153.0193 & 0.65 & 100 & 2,4-Dihydroxybenzoic acid \\
\hline OP4 & 11.74 & $\mathrm{C}_{4} \mathrm{H}_{2} \mathrm{O}_{6}$ & 145.0506 & 145.0509 & 2.07 & 100 & 2,3-Diketo-succinic acid \\
\hline OP5 & 14.08 & $\mathrm{C}_{11} \mathrm{H}_{6} \mathrm{O}_{4}$ & 201.0761 & 201.0763 & 0.99 & 100 & 2-Methyl-5,8-diketo-1,4-naphtoquinone \\
\hline OP6 & 14.60 & $\mathrm{C}_{11} \mathrm{H}_{6} \mathrm{O}_{4}$ & 201.0756 & 201.0763 & 3.48 & 100 & 2-Methyl-5,6-diketo-1,4-naphtoquinone \\
\hline 2 & 15.35 & $\mathrm{C}_{45} \mathrm{H}_{36} \mathrm{O}_{18}$ & 863.1836 & 863.1829 & -0.81 & 100 & Procyanidin trimer[E(C)-A-E(C)-B-E(C)] \\
\hline 3 & 16.16 & $\mathrm{C}_{30} \mathrm{H}_{24} \mathrm{O}_{12}$ & 575.1216 & 575.1195 & -3.65 & 100 & Procyanidin dimer[E(C)-A-E(C)] \\
\hline OP7 & 16.81 & $\mathrm{C}_{5} \mathrm{H}_{4} \mathrm{O}_{6}$ & 159.0663 & 159.0655 & -5.03 & 100 & 2,3-Diketoglutaric acid \\
\hline 4 & 18.99 & $\mathrm{C}_{30} \mathrm{H}_{24} \mathrm{O}_{12}$ & 575.1209 & 575.1195 & -2.43 & 100 & Procyanidin dimer[E(C)-A-E(C)] \\
\hline 5 & 21.93 & $\mathrm{C}_{7} \mathrm{H}_{10} \mathrm{O}_{5}$ & 173.0845 & 173.0855 & 5.78 & 100 & Shikimic acid \\
\hline 6 & 22.66 & $\mathrm{C}_{10} \mathrm{H}_{8} \mathrm{O}_{2}$ & 159.1044 & 159.1052 & 5.03 & 100 & 1,4- Dihydroxynaphthalene \\
\hline 7 & 23.24 & $\mathrm{C}_{29} \mathrm{H}_{24} \mathrm{O}_{16}$ & 627.0991 & 627.0992 & 0.16 & 100 & [Epigallocatechin gallate-gallic acid] \\
\hline 8 & 26.21 & $\mathrm{C}_{11} \mathrm{H}_{8} \mathrm{O}_{3}$ & 187.0401 & 187.0401 & 0.00 & 100 & 5-Hydroxy-2-methyl-1,4-naphtoquinone \\
\hline 9 & 26.57 & $\mathrm{C}_{45} \mathrm{H}_{28} \mathrm{O}_{18}$ & 855.1212 & 855.1203 & -1.05 & 100 & 3',4',5,7-Tetrahydroxy-flavanone A-type trimer \\
\hline OP8 & 29.15 & $\mathrm{C}_{7} \mathrm{H}_{10} \mathrm{O}_{8}$ & 201.0315 & 201.0303 & -5.97 & 100 & 3,4,5-Trihydroxyl-2-keto-pimelic acid \\
\hline OP9 & 32.62 & $\mathrm{C}_{10} \mathrm{H}_{8} \mathrm{O}_{6}$ & 223.0252 & 223.0248 & -1.79 & 100 & 5,7-Dihydroxy-benzopyran-4-one-2-carboxylic acid \\
\hline
\end{tabular}<smiles>CC1=CC(C)C2C(C)=CC=CC2C1O</smiles>

$\mathrm{C}_{6} \mathrm{H}_{6} \mathrm{O}_{4}, 142$ (No.1) $\quad \mathrm{C}_{7} \mathrm{H}_{10} \mathrm{O}_{5}, 174$ (No.5) $\mathrm{C}_{10} \mathrm{H}_{8} \mathrm{O}_{2} 160$ (No.6) $\mathrm{C}_{11} \mathrm{H}_{8} \mathrm{O}_{3}, 188$ (No.8)

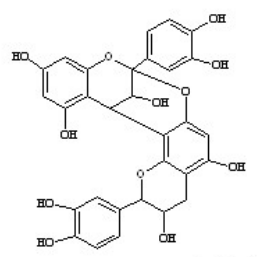

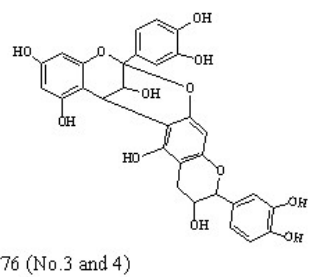

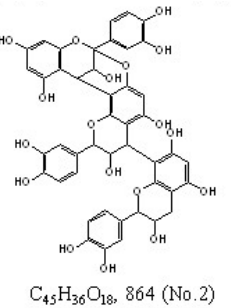
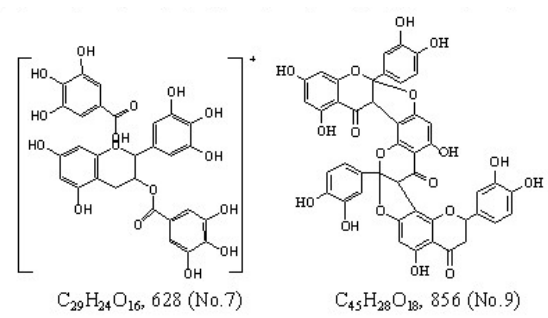<smiles>CC1CC(C)C2CCC(C)C(C1=O)C2=O</smiles>
$\mathrm{C}_{30} \mathrm{H}_{24} \mathrm{O}_{12}, 576$ (No.3 and 4)

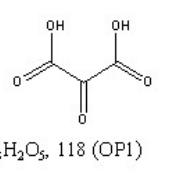<smiles>O=C(O)COC(=O)CC(=O)O</smiles>

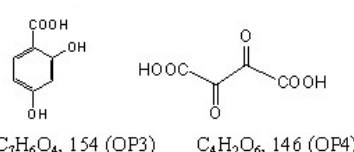<smiles>CC1CC(O)C(C)C2C(=O)C=CC(=O)C12</smiles><smiles>CCOC1C(O)CC(O)C(O)C1O</smiles><smiles>O=C1CC(O)OC2CC(O)=CC(O)C12</smiles>

Figure 4. Structures of polyphenols and their oxidative products in the peanut skins 
(A)

(B)
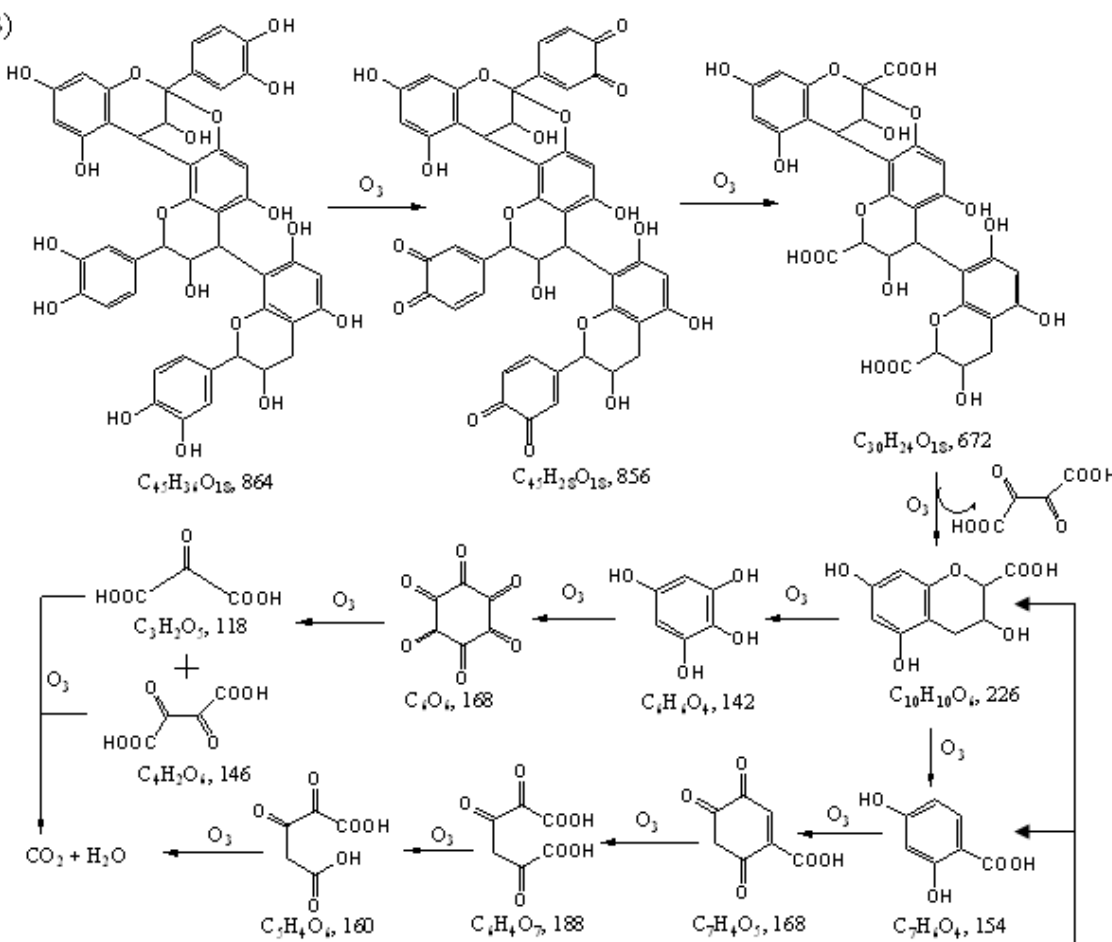

(C)

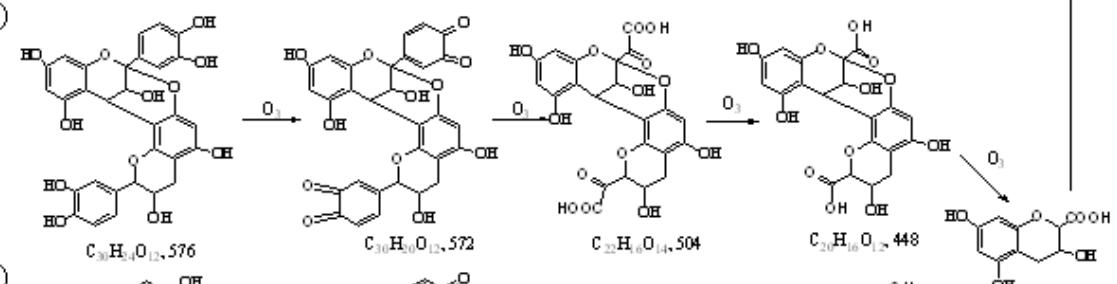

(D)

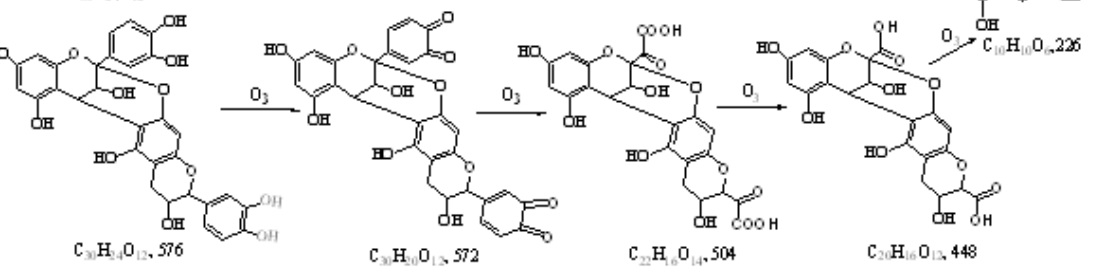

Figure 5. Ozonolysis pathways of polyphenols 1 (A), 2 (B), 3 (C) and 4 (D) in the peanut skins

The final oxidative products were $\mathrm{CO}_{2}$ and $\mathrm{H}_{2} \mathrm{O}$ within enough ozonation time (Figure $5 \mathrm{~A}$ ).

The procyanidin trimer (No. 2) is a polymer of catechin (C) or epicatechin (E) with a linkage of E (C)-A-E (C)-B$\mathrm{E}(\mathrm{C})$ (Figure 4) [22,23]. During the ozonation process, the two hydroxyls on the B ring of catechin/epicatechin were firstly oxidized to o-quinone according to the oxidative mechanism of phenols $[33,34]$. According to the Criegee mechanism of ozonolysis [35], i.e. the alkene double bonds were cleavaged by reacting with ozone, so $\mathrm{B}$ rings on the catechin/epicatechin were oxidized to the carboxyls or carbonyls, and formed the trimer of 3,5,7trihydroxy-benzopyran-2-carboxylic acid by releasing the OP4. The newly formed trimer was further decomposed to its monomer. The monomer of 3,5,7-trihydroxybenzopyran-2-carboxylic acid formed undergone two oxidation pathways. The one is that it was oxidized to the 1,2,3,5-tetrahydroxybenzene (No. 1), which was consistent with the peak area change of No. 1, i.e. it was slightly increased and then slowly decreased in peak area during the ozonation process (Figure $3 \mathrm{~A}$ ). The followed oxidation steps were the same as those of the 1,2,3,5tetrahydroxybenzene (Figure $5 \mathrm{~A}$ ). The other is that it was oxidized to the 2,4-dihydroxy-benzoic acid (OP3). The OP3 is a phenolic acid, which was rapidly oxidized to the corresponding ketonic acid. The ketonic acid was cleavaged by reacting with ozone based on the Criegee mechanism, and transformed to the 2,3,5triketohexanedioic acid, which could be cleavaged to the 2, 3-diketoglutaric acid (OP7). The final products were also $\mathrm{CO}_{2}$ and $\mathrm{H}_{2} \mathrm{O}$ within an enough ozonation time.

The phenol compounds 3 and 4 are A-type dimers ( $2 \beta$ $\mathrm{O}-7,4 \beta-6$, or $2 \beta-\mathrm{O}-7,4 \beta-8)$ of catechin or epicatechin $[22,25]$. Their oxidation processes are similar to each other, and the 3,5,7-trihydroxy-benzopyran-2-carboxylic acid is their common intermediate product (Figure $5 \mathrm{C}$ and $\mathrm{D})$. From the beginning of the intermediate product, 
the followed oxidation steps are the same as those of the procyanidin trimer (Figure $5 \mathrm{~B}$ ).

The shikimic acid (No. 5) could be oxidized by ozone with two pathways. The first one is that the three hydroxyls on the hexatomic ring were oxidized to three keto-groups, i.e. 3,4,5-trihydroxy-1-cyclohexene-1carboxylic acid was transformed to 3,4,5-triketo-1- cyclohexene -carboxylic acid [36], and then it further reacted with ozone based on the Criegee mechanism to form 2,3,4,6-tetraketo-pimelic acid. The carboxys on the both ends of 2,3,4,6-tetraketo-pimelic acid were cleavaged and formed the 2, 3-diketo-glutaric acid (OP7), which was further oxidized to the OP2 by ozone. The final oxidation products were also $\mathrm{CO}_{2}$ and $\mathrm{H}_{2} \mathrm{O}$ (Figure $6 \mathrm{~A}$ ).

(A)

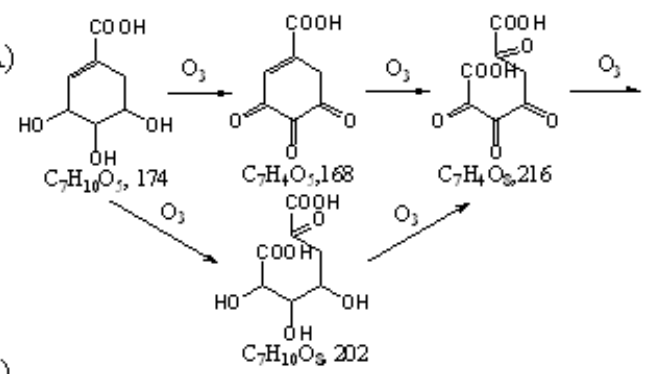

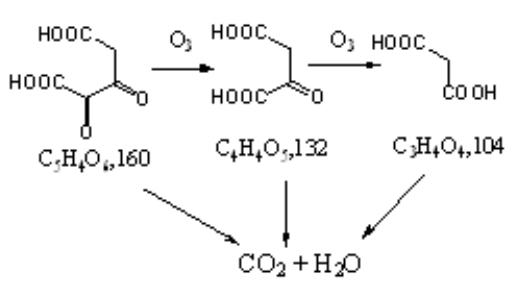

(B)

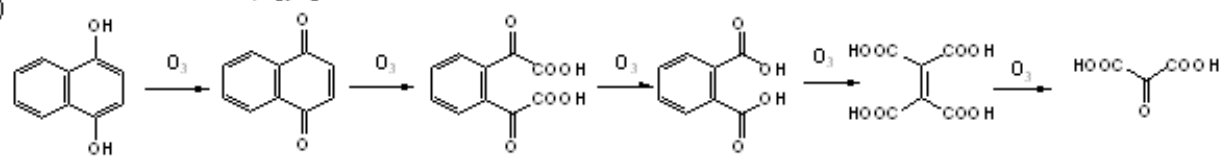

(C)
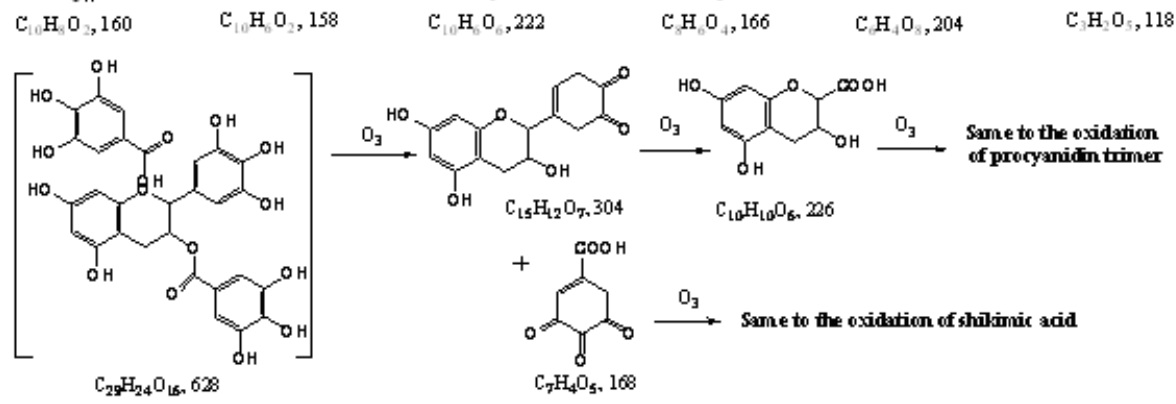

(D)

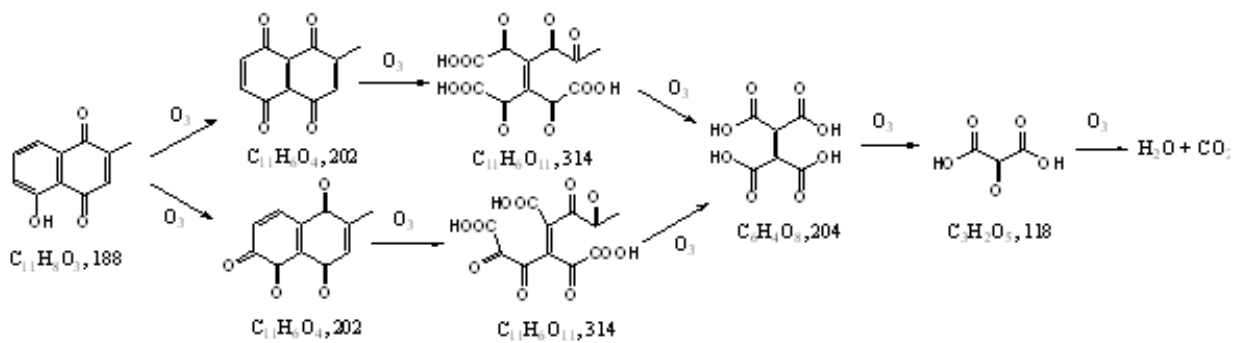

(E)

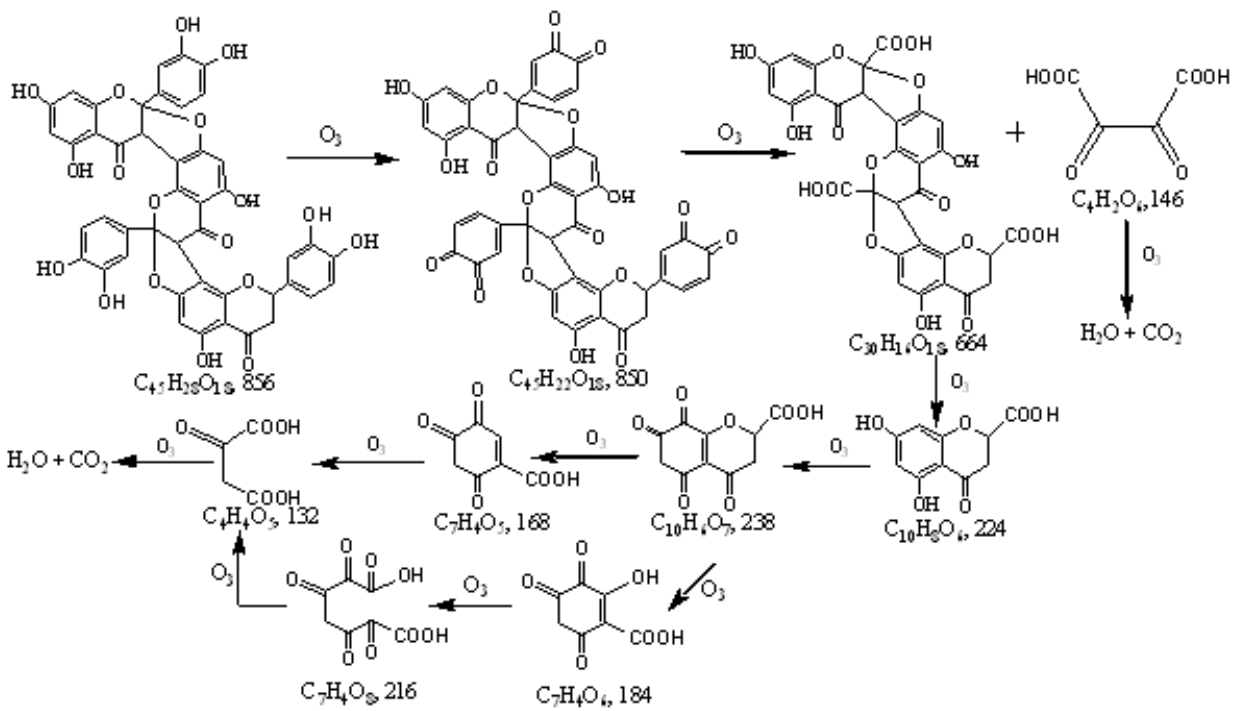

Figure 6. Ozonolysis pathways of polyphenols 5 (A), 6 (B), 7 (C), 8 (D) and 9 (E) in the peanut skins

The 1,4-dihydroxynaphalene (No. 6) was firstly oxidized to 1,4-naphthaquinone based on the oxidation mechanism of phenols, and then the new formed double bond on the benzene ring was cleavaged by ozone based on the Criegee mechanism to form benzene-1,2-diformylcarboxylic acid. The two carboxyls formed in the 
benzene-1,2-diformyl-carboxylic acid were cleavaged and transformed to phthalandione. For the phthalandione, the double bonds on the 3 and 5 sites of benzene ring were oxidative-cleavaged to form the 2,3-dicarboxy-2-butene diacid, and the final oxidative product was the OP1 (Figure 6 B).

The conjugate of epigallocatechin gallate and gallic acid (No. 7) was dissociated to epigallocatechin and gallic acid by ozone, which were rapidly oxidized to the corresponding ketones (Figure $6 \mathrm{C}$ ). The three hydroxyls on the $\mathrm{B}$ ring of the epigallocatechin were oxidized to triketone of the epigallocatechin, and then transformed to 3,5,7-trihydroxy-benzopyran-2-carboxylic acid. The following ozonation processes were the same as those of the procyanidin trimer (No. 2).

The 5-hydroxy-2-methyl-1,4-naphtoquinone (No. 8) was firstly oxidized to much 2-methyl-1,4,5,8naphtoquinone and few 2-methyl-1,4,5,6-naphtoquinone, and then they were oxidized and cleavaged at the sites of the double bond based on the Criegee mechanism, and then formed the corresponding ketonic acids. The common intermediate product was the 2,3-dicarboxy-2butene diacid, and the final oxidative product was the OP1 (Figure 6 D).

The polyphenol 9 is an A-type trimer of flavanone with a linkage of $[2 \beta-O-7,3 \beta-8]$. The two hydroxyls on the B ring of flavanone were firstly oxidized to $o$-quinone based on the oxidation mechanism of phenols (Figure $6 \mathrm{E}$ ). The 5,7-dihydroxy-benzopyrone-2-carboxylic acid formed in the oxidation process is an intermediate product, which is different from the intermediate product (3,5,7-trihydroxybenzopyran-2-carboxylic acid) in the oxidation process of polyphenols 2, 3, 4, and 7. It was further decomposed through two pathways. The first pathway is that it was oxidized to 6-alkenyl-2,4,5-triketo-heptanaphthenic acid and then the OP2 was formed at the role of ozone. The second one is that it was oxidized to 1-alkenyl-2-hydroxy3,4,6-triketo-heptanaphthenic acid, which was further reacted with ozone based on the Criegee mechanism, and formed the product 2,3,5,6-tetraketo-pimelic acid. The keto-pimelic acid was decomposed to the OP2 by ozone, and the final products were $\mathrm{CO}_{2}$ and $\mathrm{H}_{2} \mathrm{O}$.

\section{Conclusions}

Our study shows that ozone, as a strong oxidation agent, can severely destroy the polyphenols in peanut skins. Many studies have verified that the antioxidant capacity of peanut skins is closely correlated to the contents of polyphenols. Thus, the destruction of polyphenols in peanut skins decreases their antioxidant capacity. HPLC can separate efficiently the polyphenols in peanut skin extracts, and Q-TOF/MS can measure accurately their molecular weights. Based on the results of HPLC-QTOF/MS, and referred to the reported literatures, nine polyphenols were separated and identified. Most intermediate products of polyphenols were ketonic acids, and the final products were $\mathrm{CO}_{2}$ and $\mathrm{H}_{2} \mathrm{O}$. The oxidation mechanism of phenols and the Criegee mechanism of ozonolysis can be used to interpret the ozonolysis pathways of polyphenols in the peanut skin extracts.

\section{Acknowledgements}

Financial support for the authors' work was obtained from the Agricultural Department of China, the Public Benefit Research Foundation (201203037). The authors are grateful to College of Food Science \& Engineering, Shandong Agricultural University for excellent support.

\section{References}

[1] Yu JM., Mohamed A., Ipek G., "Effects of processing methods and extraction solvents on concentration and antioxidant activity of peanut skin phenolics,” Food Chemistry, 90. 199-206. 2005.

[2] Tiwari BK., O’Donnell CP., Muthukumarappan K., Cullen PJ., "Anthocyanins and color degradation in ozone treated blackberry juice,” Innovative Food Science and Emerging Technologies, 10. 70-75. 2009

[3] Yu J., Ahmedna M., Goktepe I., "Potential of peanut skin phenolic extract as antioxidative and antibacterial agent in cooked and raw ground beef," International Journal of Food Science and Technology, 45.1337-1344. 2010.

[4] Jackman RL., Yada RY., Tung MA., Speers RA., “Anthocyanins as food colorants -a review,” Journal of Food Biochemistry, 11. 201-247. 1987.

[5] Rein MJ., Heinonen M., "Stability and enhancement of berry juice color," Journal of Agricultural and Food Chemistry, 52. 3106-3114. 2004.

[6] Williams JH., Phillips TD., Jolly PE., Stiles JK., Jolly CM., Aggarwal D., "Human aflatoxicosis in developing countries: a review of toxicology, exposure, potential health consequences, and interventions,” The American Journal of Clinical Nutrition, 80. 1106-1122. 2004.

[7] Netke SP., Roomi MW., Tsao C, Niedwiecki A., “Ascorbic acid protects Guinea pigs from acute aflatoxin toxicity,” Toxicology and Applied Pharmacology, 143. 429-435. 1997.

[8] Das C., Mishra HN., "Effect of aflatoxin $B_{1}$ detoxification on the physicochemical properties and quality of ground nut meal," Food Chemistry, 70. 483-487. 2000.

[9] Haskard C., Binnion C., Ahokas J., "Factors affecting the sequestration of aflatoxin by Lactobacillus rhamnosus strain GG," Chemico-Biological Interactions, 128. 39-49. 2000.

[10] McKenzie KS., Sarr AB., Mayura K., Bailey RH., Miller DR., Rogers TD., Norred WP., Voss KA., Plattner RD., Kubena LF., Phillips TD., "Oxidative degradation and detoxification of mycotoxins using a novel source of ozone," Food Chemistry and Toxicology, 35. 807-820. 1997.

[11] Akbas MY., Ozdemir M., "Effect of different ozone treatments on aflatoxin degradation and physicochemical properties of pistachios," Journal of the Science of Food and Agriculture, 86. 2099-2104. 2006.

[12] Zorlugenç B., Zorlugenç FK., Öztekin S., Evliya IB., “The influence of gaseous ozone and ozonated water on microbial flora and degradation of aflatoxin $\mathrm{B}_{1}$ in dried figs," Food Chemistry and Toxicology, 46. 3593-3597. 2008.

[13] Guzel-Seydim Z., Greene AK., Wolososhuk CP., "Use of ozone in the food industry," Lebensmittel-Wissenschaft \& Technologie, 37. 453-460. 2004.

[14] Alencar ER., Faroni LRD., Soares NFF., Carvalho MCS., Pereira KF., "Effect of the ozonization process on the quality of peanuts and crude oil,” Reviata Brasileira de Engenharia Agrĺcola Ambiental, 15. 154-160. 2011.

[15] Diao EJ., Shan CP., Hou HX., Wang SS., Li MH., Dong HZ., "Structures of the Ozonolysis Products and Ozonolysis Pathway of Aflatoxin $\mathrm{B}_{1}$ in Acetonitrile Solution,” Journal of Agricultural and Food Chemistry, 60. 9364-9370. 2012.

[16] Mortishire-Smith RJ., O’Connor D., Castro-Perez JM., Kirby J., "Accelerated throughput metabolic route screening in early drug discovery using high-resolution liquid chromatography/quadrupole time-of-flight mass spectrometry and automated data analysis," Rapid Communications in Mass Spectrometry, 19. 2659-2670. 2005.

[17] Bateman KP., Castro-Perez J., Wrona M., Shockor JP., Yu K., Oballa R., Nicoll-Griffith DA., "MS ${ }^{\mathrm{E}}$ with mass defect filtering 
for in vitro and in vivo metabolite identification,” Rapid Communications in Mass Spectrometry, 21. 1485-1496. 2007.

[18] Lin ZS., Le J., Hong ZY., "Liquid chromatography-quadrupoletime-of-flight mass spectrometry and its application in the metabolism (metabolomics) research of traditional Chinese medicines,” Chinese Pharmaceutical Journal, 47. 401-405. 2012.

[19] Qiu JY., Chen LL., Zhu QJ., Wang DJ., Wang WL., Sun X., Liu XY., Du FL., "Screening natural antioxidants in peanut shell using DPPH-HPLC-DAD-TOF/MS methods," Food Chemistry, 135. 2366-2371. 2012.

[20] Appeldoorn MM., Sanders M., Vincken JP., Cheynier V., Guernevé CL., Hollman PCH., Gruppen H., "Efficient isolation of major procyanidin A-type dimers from peanut skins and B-type dimers from grape seeds," Food Chemistry, 117. 713-720. 2009.

[21] Palafox-Carlos H., Yahia EM., González-Aguilar GA., "Identification and quantification of major phenolic compounds from mango (Mangifera indica, cv. Ataulfo) fruit by HPLC-DADMS/MS-ESI and their individual contribution to the antioxidant activity during ripening," Food Chemistry, 135.105-111. 2012.

[22] Sarnoski PJ., Johnson JV., Reed KA., Tanko JM., O’Keefe SF., "Separation and characterisation of proanthocyanidins in Virginia type peanut skins by LC-MS", Food Chemistry, 131. 927-939. 2012.

[23] Reed KA., "Identification of phenolic compounds from peanut skin using HPLC-MS ${ }^{\mathrm{n}}$," Doctoral Dissertation, Virginia Polytechnic Institute and State University, USA. p 195-295. 2009.

[24] Lazarus SA., Adamson GE., Hammerstone JF., Schmitz HH., "High-performance liquid chromatography/mass spectrometry analysis of proanthocyanidins in foods and beverages," Journal of Agricultural and Food Chemistry, 47. 3693-3701. 1999.

[25] Lou HX., Yamazaki Y., Sasaki T., Uchida M., Tanaka H., Oka S., "A-type proanthocyanidins from peanut skins," Phytochemistry, 51. 297-308. 1999.

[26] Lou HX., Yuan HQ., Ma B., Ren DM., Ji M., Oka S., "Polyphenols from peanut skins and their free radical-scavenging effects," Phytochemistry, 65. 2391-2399. 2004.
[27] Talcott ST., Passeretti S, Duncan CE, Gorbet DW. "Polyphenolic content and sensory properties of normal and high oleic acid peanuts," Food Chemistry, 90. 379-388. 2005.

[28] Lee SC., Jeong SM., Kim SY., Park HR., Nam KC., Ahn DU., "Effect of far-infrared radiation and heat treatment on the antioxidant activity of water extracts from peanut hulls," Food Chemistry, 94. 489-493. 2006.

[29] Davis JP., Dean LL., Price KM., Sanders TH., "Roast effects on the hydrophilic and lipophilic antioxidant capacities of peanut flours, blanched peanut seed and peanut skins," Food Chemistry, 119. 539-547. 2010.

[30] de Camargo AC., de Souza Vieira TM., Regitano-D’Arce FMA. Calori-Domingues BMA., Canniatti-Brazaca SG., "Gamma radiation effects on peanut skin antioxidants," International Journal of Molecular Science, 13. 3073-3084. 2012.

[31] Huang HN., Hu XH., Huang HQ., Yan L., Chen DS., Ou-yang GL., Zhuo HQ., "Polymer characteristics of catechin and catechin- $\mathrm{Ge}^{4+}$ measured with a technology of mass spectrometry," Chinese Journal of Analytical Chemistry, 1. 52-56. 2006.

[32] Devlin HR., Harris IJ., "Mechanism of the oxidation of aqueous phenol with dissolved oxygen," Industrial and Engineering Chemistry Fundamentals, 23. 387-392. 1984.

[33] Eftaxias A., Font J., Fortuny A., Giralt J., Fabregat A., Stüber F., "Kinetic modelling of catalytic wet air oxidation of phenol by simulated annealing," Applied Catalysis B: Environmental, 33. 175-190. 2001.

[34] Portela Miguélez JR., López Bemal J., Nebot Sanz E., Martínez de la Ossa E., "Kinetics of wet air oxidation of phenol," Chemical Engineering Journal, 67.115-121. 1997.

[35] Criegee R., "Mechanism of ozonolysis," Angewandte Chemie International Edition in English, 14. 745-752. 1975.

[36] Millican RC., "A thiobarbituric acid assay for shikimic acid," Analytical Biochemistry, 6. 181-192. 1963. 